\title{
EDUCAÇÃO AMBIENTAL EMANCIPATÓRIA EM MANGUINHOS/RJ: UMA ESCOLA CERCADA DE ÁGUA POR TODOS OS LADOS
}

\author{
BRANDÃO, Roberto Eduardo Albino'; \\ FERREIRA, Ariene dos Santos²; \\ CAMPOS, Franciele Pereira ${ }^{3}$, \\ VASCONCELLOS, Maria das Mercês Navarro", \\ BONATTO, Maria Paula de Oliveira ${ }^{5}$; \\ DOMINGOS, Patrícia 6 .
}

\section{INTRODUÇÃO}

A questão socioambiental, ainda um desafio para a sociedade, é também uma temática integradora de saberes, que convida à interdisciplinaridade na escola e à atuação sobre a realidade, para transformá-la em direção à emancipação. Neste trabalho se assume a vertente da Educação Ambiental Emancipatória (LOUREIRO, 2007), que reconhece a necessidade de transformações nas relações de poder dentro da sociedade para se alcançar o pleno desenvolvimento da maioria (LOUREIRO, 2007). As práticas escolares de EA, muitas vezes restringem-se às atividades que poderiam ser reconhecidas como conservadoras (LAYRARGUES, 1999) ou segundo uma vertente pragmática, como proposto por Layrargues e Lima (2014). A opção por uma perspectiva transformadora, significa incluir a discussão política de causas e consequências da chamada crise ambiental e que envolvem as questões temáticas propriamente ditas, que no caso deste trabalho, desenvolvido no CIEP Pres. Juscelino Kubitschek é a situação dos rios que atravessam a comunidade e terminam cercando a escola em seu desague. O fio condutor é a bacia hidrográfica, que permite uma visão integrada do território (TUNDISI, 2014), de sua ocupação, usos históricos, ciclos hidrossociais (SWYNGEDOUW, 2004) e as consequências desse processo. Objetiva-se o desenvolvimento da percepção em

\footnotetext{
${ }^{1}$ Secretaria Municipal de Educação da cidade do Rio de Janeiro - SME / edu@roberto.bio.br

${ }^{2}$ Universidade do Estado do Rio de Janeiro - UERJ/IBRAG/DBV/LabAlgas / ariene.sferreira@gmail.com

${ }^{3}$ Universidade Federal do Rio de Janeiro / licenciosidade@gmail.com

${ }_{5}^{4}$ Fundação Oswaldo Cruz - FIOCRUZ / mercesnavarro2014@gmail.com

${ }^{5}$ Fundação Oswaldo Cruz - FIOCRUZ / bonattofiocruz@gmail.com

${ }^{6}$ Universidade do Estado do Rio de Janeiro - UERJ/IBRAG/DBV/LabAlgas / patvitesse@gmail.com
} 
alunos e professores de que a escola está imersa num território cujo contexto é de injustiça ambiental.

\section{METODOLOGIA}

As atividades aqui apresentadas fazem parte de um projeto de Educação Ambiental realizado no CIEP Juscelino Kubitschek (JK), localizado no território de Manguinhos/RJ e contou com a participação de professores de ciências, geografia e história, buscando dialogar com os conteúdos curriculares dessas áreas. O CIEP está situado na região entre os rios Faria-Timbó e Jacaré que juntos encontram o canal do Cunha, contribuinte da Baía de Guanabara e tomou como referência o conceito de ciclo hidrossocial para realizar uma discussão socioambiental e integrada da região. A ação se apoiou em atividades de campo, sala de aula e experimentação. Primeiramente foi realizada uma atividade utilizando-se um acervo de imagens para observar algumas alterações no tempo/espaço no território de Manguinhos. Os alunos destacavam as transformações para a conformação atual do território e as referências perdidas com o tempo.

A atividade de campo foi uma visita ao trecho da sub-bacia do canal do Cunha que cerca a escola, para a realização de um diagnóstico rápido, seguindo como roteiro um protocolo de avaliação rápida (CALLISTO et al., 2002) simplificado e mapa orientadores (Google Maps). No roteiro os alunos, em grupo, faziam as anotações que resultaram numa classificação quanto ao estado de alteração do ambiente (presença de óleo e lixo nas águas, ocupação das margens, dentre outros), enquanto no mapa plotavam o que consideravam referência para seu cotidiano. No encontro dos rios foram realizadas atividades experimentais e 0 desdobramento consistiu em trabalhos de pesquisa em grupo. Uma exposição com os resultados do trabalho de campo permitiu conhecer a diferença entre as percepções de alunos e professores sobre o território.

\section{RESULTADOS E DISCUSSÃO}

O desinteresse de grande parte dos estudantes nessa unidade escolar pública municipal, pelo processo de ensino-aprendizagem, por algumas disciplinas e 
particularmente por Ciências, é facilmente percebido. Associa-se a esse fato o baixo investimento na melhoria das condições de vida no território de Manguinhos, de forma geral, bem como nas condições de trabalho e estudo dessa escola, em especial, tornando essa comunidade marginalizada, no que se refere à sensação de pertencimento ao local, fruto do modelo de desenvolvimento capitalista/individualista. Um agravante a ser considerado são as frequentes interrupções de aula em virtude da ocorrência de conflitos armados que atinge todo o território, somente entre setembro/2015 a abril/2016 foram registrados pela grande mídia 31 conflitos, muitos acompanhados de mortes, atingindo inclusive um responsável da escola. O número certamente é maior, uma vez que vários eventos não saem publicados. Muitas dessas ocasiões inviabilizam a realização de aulas no CIEP, o que caracteriza um cenário de descontinuidade das aulas e de necessidade constante de revisão de planejamentos. Essa situação tende a melhorar na medida em que os servidores públicos da educação, que trabalham nesse território, considerem os estudantes/moradores como cidadãos completos, estando ao lado deles e/ou colaborando para sua emancipação. Mas até que ponto podemos dizer que avançamos no sentido da emancipação dos estudantes? Trabalhamos com a perspectiva de Loureiro (2007, p.158):

[...] há emancipação quando agimos para superar e superamos: (1) relações paternalistas e assistencialistas que reproduzem a miséria (intelectual e econômica); (2) uma educação que impede a capacidade crítica de pensar e intervir de educadores-educandos; (3) a apropriação privada do conhecimento científico; (4) práticas políticas que viciam a democracia e sufocam o desejo da participação, garantindo o privilégio de oligarquias...; (5) relações de classe que condenam milhões a uma condição indigna, de precariedade na luta pela sobrevivência [...].

Em conexão com essa perspectiva emancipatória, observa-se a indissociabilidade entre educação, ambiente e a luta contra desigualdades que excluem os alunos das classes desfavorecidas das oportunidades de conhecimento aos quais têm direito, sobretudo em escolas que estão situadas em territórios favelizados, como é o caso do CIEP JK.

Nesse sentido o trabalho se apoiou na valorização e reconhecimento do território no entorno da escola, seguindo a concepção Freiriana (FREIRE, 2001), 
onde os estudantes destacaram seus problemas e referências cotidianas, para o estímulo ao estudo de ciências.

O trabalho com imagens sobre as transformações do território utilizou um acervo da FIOCRUZ (Projeto Território em Transe) e foi o início para o estímulo ao estudo das questões que seriam apontados no trabalho de campo que se deu no trecho final da sub-bacia do canal do Cunha que cerca a escola. Os rios são considerados uma referência local, recebendo denominação própria e relatados por antigos moradores como área de lazer quando suas águas eram limpas.

Durante o trajeto do trabalho de campo os alunos apontaram pontos negativos (presença de lixo, ocupação irregular das margens, presença de ratos) e positivos (árvores de frutas, flores, moradores colaboradores). As imagens e mapas gerados formaram a exposição "Rolezinho-na-minha-água" para pais, alunos e professores e foi guiada pelo Clube de Ciências da JK, criado no projeto. Um produto importante da atividade foi a construção de uma cartografia socioambiental à luz da percepção dos alunos, onde seu cotidiano foi destacado e valorizado no mapa produzido. Neste mapa foram plotados todos os aspectos destacados pelos 5 grupos que trabalharam isoladamente. Alguns aspectos valorizados não necessariamente foram avistados durante a atividade, mas permaneciam como referências marcantes de sua vivência no território. Como exemplo o relato de garças comendo ratos e um episódio de um jacaré que teria comido uma galinha.

Embora tenham feito relato oral de terem visto defunto(s) jogado(s) no rio, esse item não foi registrado no mapa de nenhum dos grupos, o que demonstra que parte deste relato ali captado foi silenciado, provavelmente respeitando limitações tácitas impostas na favela pelo medo e insegurança, mesmo que de forma inconsciente. Alguns professores surpreenderam-se com a ausência de melhorias, em função de numerosas obras já realizadas. Provavelmente contavam com uma melhoria em função de parte da comunidade ter sido alvo do Programa de Aceleração do Crescimento (PAC) do governo federal. Entretanto a obra não alcançou a comunidade como um todo, deixando de lado várias localidades (Varginha, Green Vile, Mandela de Pedra 1 e 2 e mesmo parte do setor denominado de Manguinhos, como são chamadas pelos moradores). Os professores demonstraram surpresa com a paisagem de degradação, com a presença de jacarés e lançamentos clandestinos nos rios oriundos de casas e instituições vizinhas, revelando que a escola, em geral, realiza nenhum, ou muito poucos, trabalhos 
didáticos explorando o entorno da escola ou mesmo a realidade mais próxima dos alunos.

As observações foram temas de pesquisa posterior em grupo. As pesquisas demandavam um trabalho mais sistematizado e, apesar dos assuntos terem sido destacados por eles, de se contar com recursos lúdicos, iconográficos e de informática, alguns afirmavam que "parecia aula" e a produção dos resultados foi bastante diferenciada entre os grupos.

Foi uma preocupação constante discutir com os alunos a origem da atual situação dos rios, fazendo-os perceber que aquela era uma região de foz, deságue dos rios e que, portanto, ao chegar ali os rios já acumulavam todo tipo de degradação realizada a montante. Essa discussão permitiu incorporar alguns dos elementos que definem o ciclo hidrossocial (SWYNGEDOUW, 2004) e contribuiu para desconstruir a ideia de culpabilizar as comunidades moradoras daquela região como os responsáveis pela situação de seu entorno. Na verdade, são as áreas menos valorizadas, mais degradadas, mais impactadas ambientalmente e menos assistidas pelo poder público, aquelas destinadas historicamente às populações menos favorecidas, caracterizando um quadro de injustiça ambiental (ACSELRAD, 2010).

\section{CONCLUSÕES}

Destaca-se a dedicação, empenho e capacidade de auto-organização dos estudantes, na maioria das atividades do projeto, o que também motivou professores. O maior empenho dos alunos esteve relacionado às iniciativas de maior dinâmica e participação, como aulas-passeio, apontando um caminho para despertar nesse grupo o desejo de desenvolver seus estudos. O debate em torno da bacia hidrográfica, na qual a escola se situa, literalmente entre dois rios, é extremamente necessário, e reveste-se de inúmeras possibilidades de transformação social a partir da emancipação dos estudantes. A percepção dos alunos a respeito de seu próprio entorno mudou, contribuindo para criar um estranhamento sobre a situação dada que se tornava naturalizada por muitos. Passaram a conhecer o nome dos rios durante a atividade e valorizaram relatos de antigos moradores sobre outra relação já existente entre a comunidade e aquelas águas. Despertaram para um desejo de mudar a situação. O trabalho aponta para os problemas locais como percebidos por 
alunos e professores, denunciando a necessidade urgente de ação do poder público sob o princípio da equidade, investindo onde mais precisa, bem como garantindo espaços de construção coletiva dentro da escola.

\section{REFERÊNCIAS}

ACSELRAD, H. Ambientalização das lutas sociais - o caso do movimento por justiça ambiental. Estudos Avançados. 2010. 24 (68) 103-119.

CALLISTO, M., FERREIRA, W.R., MORENO, P., GOULART, M. e PETRUCIO, M. Acta Limnológica Brasiliensis. 2002. 14 (1): 91-98.

FREIRE, Paulo. Pedagogia do oprimido. 31. ed. Rio de Janeiro: Paz e Terra, 2001. $184 \mathrm{p}$.

LAYRARGUES, P. P. ; LIMA, G.F.C. As macrotendências político-pedagógicas da educação ambiental brasileira. Ambiente \& Sociedade jan.-mar, 2014. São Paulo v. XVII, n. 1 p. 23-40.

LAYRARGUES, P.P. A resolução de problemas ambientais locais deve ser um temagerador ou a atividade-fim da educação ambiental? In: REIGOTA, M. (Org.). Verde Cotidiano: o meio ambiente em discussão. Rio de Janeiro: DP\&A Editora. p. 131148. 1999.

LOUREIRO, Carlos Frederico B. Emancipação. In: Ferraro Júnior, L. A. (Org.). Encontros e caminhos: formação de educadoras (es) ambientais e coletivos educadores. 1 ed. Brasília: Ministério do Meio Ambiente, 2007, v. 2, p. 157-170.

SWYNGEDOUW, E. Social Power and the Urbanization of Water: Flows of Power. Oxford Geographical and Environmental Studies. Oxford, 2004.

TUNDISI, J.G. (coord.) Recursos hídricos no Brasil: problemas, desafios e estratégias para o futuro. Rio de Janeiro: Academia Brasileira de Ciências, 2014. 76 p.

\section{Fontes Financiadoras}

FAPERJ; CETREINA/SR1-UERJ; PROATEC/DEPESQ/SR2-UERJ 